\title{
Knowledge, attitudes, and impact of COVID-19 pandemic among neurology patients in Jordan: a cross-sectional study
}

\author{
Mohammad Athamneh ${ }^{1 *}$ (D), Qais Sa'di ${ }^{2}$ (D) Belal Aldabbour ${ }^{3}$ (D) Yousef Khader $^{4}$ (D) and Waleed Batayha ${ }^{2}$ (D)
}

\begin{abstract}
Background: The impacts of the COVID-19 pandemic on health services offered to patients with noncommunicable diseases, including chronic neurological illnesses, are diverse and universal. We used a self-reported questionnaire to investigate these impacts on neurology patients in Jordan and assess their knowledge and attitudes towards the pandemic.

Results: Most respondents had positive attitudes towards the COVID-19 pandemic, with 96\% reporting they believed in the seriousness of the pandemic and adhered to prevention measures. Nearly $97 \%$ resorted to the internet and media outlets for medical information about the pandemic. About one in five clinic visitors had their appointments delayed due to interruption of health services. A similar portion of patients with MS, epilepsy, and migraine or tension headache reported medication interruptions during the pandemic. One in two patients reported new events or worsening illness since the start of the pandemic, and sleep disturbances were reported by nearly one in three patients who had epilepsy or headache.
\end{abstract}

Conclusion: The COVID-19 pandemic's impacts on patients with neurological illnesses in Jordan were deep and diverse. Meanwhile, the majority of surveyed neurology patients demonstrated a positive attitude towards the pandemic.

Keywords: SARS-CoV-2, Epidemic, Jordan, Health Services, Disease control

\section{Background}

The impact of pandemics on healthcare systems is welldocumented, particularly in countries with limited resources. Routine health services decreased by an estimated 18\% during the 2014-2015 Ebola outbreak in West Africa, resulting in thousands of potentially preventable deaths [1]. Also, following the severe acute respiratory syndrome (SARS) outbreak in China, clinic and emergency room visits at a hospital in Taipei City dropped to $55 \%$ and $45 \%$, respectively, in 2003 compared with the previous year [2]. A study in Qatar revealed that the overall utilization of primary health care services

\footnotetext{
* Correspondence: athamneh1986@hotmail.com

'Department of Neuroscience, Faculty of Medicine, Yarmouk University, Irbid, Jordan

Full list of author information is available at the end of the article
}

declined to $50 \%$ in April of 2020 during the surge of local Coronavirus disease of 2019 (COVID-19) spread [3]. In Spain, a negative effect was observed on up to $85 \%$ of healthcare quality standards in Catalonia in March and April of 2020 [4]. Also, in the USA, a CDC report found a substantial reduction in pediatric vaccine orders following the COVID-19 emergency declaration in March of 2020 [5].

A growing body of literature suggests that severe acute respiratory syndrome coronavirus 2 (SARS-CoV-2), causing COVID-19, has neurotropic characteristics [69]. Neurologists have other considerations regarding the impact of the virus on their patients. Many neurological diseases necessitate long-term and profound immune suppression [10]. In addition, patients with neuromuscular diseases represent a particularly vulnerable group to
Springer Open (c) The Author(s). 2021 Open Access This article is licensed under a Creative Commons Attribution 4.0 International License, which permits use, sharing, adaptation, distribution and reproduction in any medium or format, as long as you give appropriate credit to the original author(s) and the source, provide a link to the Creative Commons licence, and indicate if changes were made. The images or other third party material in this article are included in the article's Creative Commons licence, unless indicated otherwise in a credit line to the material. If material is not included in the article's Creative Commons licence and your intended use is not permitted by statutory regulation or exceeds the permitted use, you will need to obtain permission directly from the copyright holder. To view a copy of this licence, visit http://creativecommons.org/licenses/by/4.0/. 
which the infection can be potentially fatal [11]. The most immediate and possibly the broadest short-term impact of the pandemic on neurology patients could be the limitations on accessibility to healthcare and medications, especially in communities with uncontrolled spread or as a byproduct of strict prevention measures.

In Jordan, the authorities have since March 17, 2020, imposed a number of local and nationwide curfews and lockdowns in a bid to curb local spread and prevent overwhelming the healthcare system [12]. Subsequently, many hospitals had to discontinue outpatient and clinic services, and elective procedures were postponed for weeks or months. Also, many patients faced difficulties refilling prescriptions and obtaining regular medications. On the other hand, an online survey of 5274 persons from Jordan found that approximately four out of every ten participants experienced quarantine-related anxiety [13], illustrating one aspect of the pandemic's impact on the health of the Jordanian population. This study aimed to explore the attitude towards the COVID-19 pandemic and its impacts on the health of patients with neurological illnesses including multiple sclerosis (MS), epilepsy, and primary tension or migraine headache.

\section{Methods}

This is a cross-sectional study that was conducted between November and December of 2020. Patients aged $\geq$ 18 years who presented with a neurological complaint at outpatient neurology clinics at the hospital affiliated with the second and last authors during the study period were invited to participate in this study. This hospital is a tertiary facility, and it is the main governmental hospital in the city. After obtaining ethical approval, a paper-based questionnaire was administered to patients visiting the hospital's neurology clinics. Written consent was obtained from each patient prior to the administration of the questionnaire. The questionnaire included questions about the attitude of patients towards the pandemic and the impact they feel it had on their lives and illnesses. Specific questions were included in the questionnaire relevant to those with an established diagnosis of MS, epilepsy, or primary tension or migraine headaches. Additionally, as sleeping disturbances can exacerbate epilepsy and headache, patients with these two conditions were asked about the occurrence of sleep disturbances during the pandemic and the predisposing factors. Patients were excluded if they presented with non-neurological complaints. Additionally, patients with advanced dementia or severe intellectual disability were excluded if their conditions precluded meaningful communication or affected their ability to answer the questionnaire independently and reliably. Statistical analysis of the collected data was conducted using IBM SPSS software version 25 (SPSS Inc., Chicago, IL, USA).
Descriptive statistics were performed for all variables to calculate frequencies and percentages.

\section{Results}

A total of 562 patients presented to neurology outpatient clinics during the study period, of whom 506 (90.03\%) patients responded to the questionnaire. Patients under 40 years of age constituted over half the sample. Men constituted $45.45 \%$ of the sample. Five patients only $(0.98 \%)$ reported a previous documented infection with COVID-19. The majority of patients $(81.42 \%)$ presented to the clinic for follow-up, while $18.57 \%$ stated that this was their first visit. One fifth $(19.36 \%)$ of patients reported that their visit was delayed due to the pandemic and the lockdowns. Most patients (88.14\%) believed in the existence of COVID-19 virus and adhered to preventive measures, and $79.84 \%$ agreed that lockdowns were necessary to control the spread of the pandemic among the population. Only $1.97 \%$ of patients obtained pandemic-related information from doctors and medical sources, while the vast majority were depending on the internet and media to seek necessary information. Table 1 illustrates the characteristics of the study sample.

Among the 506 participants, 80 (15.81\%) had MS. About $73.75 \%$ of patients with MS were females and $77.50 \%$ were 40 years old or younger. Thirty-five patients (43.75\%) reported experiencing at least one MS relapse since the start of the pandemic. Of those, $30(88.24 \%)$ were admitted to the hospital, while three $(8.82 \%)$ patients have rejected admission for concerns regarding the COVID-19 pandemic, and one (2.94\%) did not seek medical advice for non-pandemic related reasons. Seventy-one $(88.75 \%)$ patients with MS had been on a disease-modifying treatment (DMT), while nine (11.25\%) were not receiving any treatment due to either medical or financial reasons. Beta-interferon $(n=35,43.75 \%)$ and Fingolimod $(n=30,37.50 \%)$ were the most frequently used DMTs, followed by Dimethyl Fumarate $(n=4,5.00 \%)$, and Natalizumab $(n=2,2.50 \%)$. Nine (11.25\%) patients with MS were not taking any medication. Regarding adherence to DMT during the pandemic, $13(16.25 \%)$ patients stated that they had discontinued the DMT during the pandemic, with four $(30.76 \%)$ of them stating that noncompliance was related to concerns over the immunosuppressive side effects, and three (23.07\%) reporting inability to obtain the medication due to the lockdown (Table 2).

A total of 150 patients had epilepsy, accounting for $29.64 \%$ of the study sample. Most patients with epilepsy were younger than $40(70.00 \%)$. Males and females constituted $51.33 \%$ and $48.66 \%$ respectively. Of this sample, eighty patients (53.33\%) reported an increased frequency of seizures since the start of the pandemic. Interruptions of anti-seizure medication (ASM) intake was reported by 
Table 1 Patients' demographic characteristics and their perceptions of COVID-19

\begin{tabular}{|c|c|c|c|c|}
\hline Variables & $\begin{array}{l}\text { Multiple sclerosis }(n=80) \\
n(\%)\end{array}$ & $\begin{array}{l}\text { Epilepsy }(n=150) \\
n(\%)\end{array}$ & $\begin{array}{l}\text { Headache }(n=40) \\
n(\%)\end{array}$ & $\begin{array}{l}\text { Total } \\
(n=506) \\
n(\%)\end{array}$ \\
\hline \multicolumn{5}{|l|}{ Gender } \\
\hline Male & $21(26.25)$ & 77 (51.33) & $7(17.50)$ & $230(45.45)$ \\
\hline Female & $59(73.75)$ & $73(48.67)$ & $33(82.50)$ & $276(54.55)$ \\
\hline \multicolumn{5}{|l|}{ Age group } \\
\hline $18-40$ & $62(77.50)$ & $105(70.00)$ & $0(00.00)$ & $276(54.55)$ \\
\hline $41-60$ & $17(21.25)$ & $40(26.67)$ & $26(65.00)$ & $159(31.42)$ \\
\hline$>60$ & $1(1.25)$ & $5(3.33)$ & $14(35.00)$ & $71(14.03)$ \\
\hline Previous diagnosis with COVID-19 & $1(1.25)$ & $3(2.01)$ & $1(2.50)$ & $5(0.99)$ \\
\hline \multicolumn{5}{|l|}{ Visit to the clinic } \\
\hline First visit & $4(5.00)$ & $8(5.33)$ & $12(30.00)$ & $94(18.58)$ \\
\hline Follow-up & $76(95.00)$ & $142(94.67)$ & $28(70.00)$ & $412(81.42)$ \\
\hline \multicolumn{5}{|l|}{ Appointments delayed due to the pandemic } \\
\hline Yes & $31(38.75)$ & $32(21.48)$ & $11(27.50)$ & $98(19.44)$ \\
\hline No & $49(61.25)$ & $117(78.52)$ & $29(72.50)$ & $406(80.56)$ \\
\hline \multicolumn{5}{|c|}{ Belief in the existence of the virus and adherence to prevention measures } \\
\hline Neither belief nor adherence & $3(3.75)$ & $7(4.70)$ & $1(2.50)$ & $11(4.09)$ \\
\hline Belief but without adherence & $1(1.25)$ & $10(6.71)$ & $0(0.00)$ & $11(4.09)$ \\
\hline Belief and adherence & $72(90.00)$ & $131(87.92)$ & $37(92.50)$ & $240(89.22)$ \\
\hline Belief and obsessive adherence impacting life & $4(5.00)$ & $1(0.67)$ & $2(5.00)$ & $7(2.60)$ \\
\hline \multicolumn{5}{|l|}{ Agreement with effectiveness of the lockdown } \\
\hline Effective & $74(92.50)$ & $107(71.81)$ & $36(90.00)$ & $217(80.67)$ \\
\hline Ineffective & $6(7.50)$ & $42(28.19)$ & $4(10.00)$ & $52(19.33)$ \\
\hline \multicolumn{5}{|l|}{ Source of information regarding the pandemic } \\
\hline Internet and social media & $57(71.25)$ & $72(48.32)$ & $24(60.00)$ & $153(56.88)$ \\
\hline Medical specialists & $1(1.25)$ & $2(1.34)$ & $2(5.00)$ & $5(1.86)$ \\
\hline Radio and TV & $21(26.25)$ & $71(47.65)$ & $13(32.50)$ & $105(39.03)$ \\
\hline No interest in information & $1(1.25)$ & $4(2.68)$ & $1(2.50)$ & $6(2.23)$ \\
\hline
\end{tabular}

Variability in totals is due to missing values in some variables

thirty patients (20\%), of whom $76.66 \%$ had increased seizures. In addition, sleep disturbances were reported by over a quarter of patients with epilepsy, and the majority ascribed these disturbances to the impact of the pandemic (Table 2).

In addition, 40 patients had primary migraine or tension-type headache, of which 37 (92.50\%) patients had migraine headache, and three $(7.50 \%)$ had tension headache. Females represented $82.22 \%$ of patients in this group, and $65 \%$ of all patients were younger than 40 . An increased frequency of headache since the start of the pandemic was reported by $25(62.50 \%)$ of patients in this group, and $25.00 \%$ reported interruption of their regular medication during the same period. Changes in sleep patterns were reported by $37.50 \%$ of patients in this group, and $50.00 \%$ blamed these changes to the impact of the pandemic. Of note, eight out of nine (88.8\%) patients with decreased total sleep hours experienced worsening headaches (Table 2).

Figure 1 demonstrates the frequency of reporting treatment discontinuation and worsening clinical course since the start of the pandemic in the three common neurological illnesses described in previous paragraphs.

\section{Discussion}

In this survey, most respondents had positive attitudes towards the COVID-19 pandemic. At the same time, the negative impacts of the pandemic on patients with neurological illnesses in Jordan were evident. Understanding the attitudes and beliefs of a population towards the pandemic has significant implications for implementing and planning of mitigation strategies and for vaccination campaigns. We found that most patients (96\%) who participated in the survey believed in the 
Table 2 Health challenges among MS, epilepsy, and headache patients during COVID-19

\begin{tabular}{|c|c|c|c|c|c|c|}
\hline \multirow[b]{2}{*}{ Variables } & \multicolumn{2}{|c|}{$\begin{array}{l}\text { Multiple sclerosis }(n=80) \\
n(\%)\end{array}$} & \multicolumn{2}{|c|}{$\begin{array}{l}\text { Epilepsy }(n=150) \\
n(\%)\end{array}$} & \multicolumn{2}{|c|}{$\begin{array}{l}\text { Headache }(n=40) \\
n(\%)\end{array}$} \\
\hline & Total & $\begin{array}{l}\text { Patients } \\
\text { with new } \\
\text { relapses (\%) }\end{array}$ & Total & $\begin{array}{l}\text { Patients with } \\
\text { increased } \\
\text { seizure }(\%)\end{array}$ & Total & $\begin{array}{l}\text { Patients with } \\
\text { increased } \\
\text { headache (\%) }\end{array}$ \\
\hline \multicolumn{7}{|c|}{ Discontinuation of medication (or regular infusions) } \\
\hline Yes & $13(17.57)$ & $5(38.46)$ & $30(20.13)$ & $23(76.67)$ & $10(25.00)$ & $7(70.00)$ \\
\hline No & $61(82.43)$ & $26(42.62)$ & $119(79.87)$ & $56(47.06)$ & $30(75.00)$ & $18(60.00)$ \\
\hline \multicolumn{7}{|l|}{ Reason of discontinuation } \\
\hline $\begin{array}{l}\text { Anxiety about the pandemic } \\
\text { (and/or concerns regarding immune } \\
\text { suppression side effects of DMT) }\end{array}$ & $4(30.77)$ & $2(50.00)$ & $9(34.62)$ & $7(77.78)$ & $2(20.00)$ & $1(50.00)$ \\
\hline $\begin{array}{l}\text { Restricted accessibility due to the } \\
\text { pandemic }\end{array}$ & $3(23.08)$ & $1(33.33)$ & $12(46.15)$ & $9(75.00)$ & $2(20.00)$ & $1(50.00)$ \\
\hline Others & $6(46.15)$ & $2(33.33)$ & $5(19.23)$ & $3(60.00)$ & $6(60.00)$ & $5(83.33)$ \\
\hline Change in sleep pattern & - & - & & & & \\
\hline $\begin{array}{l}\text { Fewer hours at night and during } \\
\text { the day }\end{array}$ & & & $16(10.74)$ & $13(81.25)$ & $9(22.50)$ & $8(88.89)$ \\
\hline $\begin{array}{l}\text { Fewer hours at night and more during } \\
\text { the day }\end{array}$ & & & $13(8.72)$ & $6(46.15)$ & $3(7.50)$ & $1(33.33)$ \\
\hline More hours of sleep & & & $12(8.05)$ & $5(41.67)$ & $3(7.50)$ & $0(0.00)$ \\
\hline No change & & & $108(72.48)$ & $55(50.93)$ & $25(62.50)$ & $16(64.00)$ \\
\hline Reason of change in sleep pattern & - & - & & & & \\
\hline Anxiety and fear of the pandemic & & & $14(34.15)$ & $11(78.57)$ & $4(28.57)$ & $3(75.00)$ \\
\hline $\begin{array}{l}\text { Frequent lockdowns and work } \\
\text { stoppage }\end{array}$ & & & $15(36.59)$ & $5(33.33)$ & $3(21.43)$ & $0(0.00)$ \\
\hline Others $^{\mathrm{a}}$ & & & $12(29.27)$ & $8(66.67)$ & $7(50.00)$ & $5(71.43)$ \\
\hline
\end{tabular}

Variability in totals is due to missing values in some variables

a"No specific reason" for epilepsy patients or "Headache itself" for headache patients

seriousness of the pandemic and demonstrated a positive attitude towards it such as adherence to prevention measures and support of national infection control plans. A previous national survey in April of 2020 revealed similar findings [14]. Therefore, despite different methodologies and target populations, the findings of our study reflect that awareness and positive attitude towards the pandemic among Jordanians remain high. We also found that nearly $97 \%$ of patients resorted to the internet and media outlets for medical information about the pandemic, a critical finding in an era where public perceptions about the pandemic are increasingly shaped by social media [15].

The findings of this study also reveal some aspects of how COVID-19 pandemic impacted health services in Jordan. Nearly one in five clinic visitors had their appointments delayed due to the interruptions of health services caused by the pandemic. Also, a similar percentage of patients with MS, epilepsy, and migraine or tension headache reported medication interruptions because of the pandemic and quarantine measures. On the other hand, nearly one in three patients with epilepsy or headache reported sleep disturbances, and half of those believed the pandemic was responsible. This is significant since sleep disturbance is a known trigger in both epilepsy and migraine headache [16, 17]. Finally, nearly one in two of surveyed patients reported new events or worsening illnesses since the start of the pandemic. This finding mostly is the outcome of a multitude of factors, such as medication interruptions, sleep disturbances, new social and financial stressors, limitations on accessibility to health services, pandemic-related anxiety, lifestyle changes, and others [18].

Surveys from other countries and regions reported varying but consistent findings underpinning the impacts of the COVID-19 pandemic. For instance, surveys that have been published recently reported that between 4 and $35 \%$ of persons with epilepsy had seizure worsening during the pandemic, and the worsening was mainly correlated with epilepsy severity, sleep disturbances, and COVID-19-related factors [16, 18]. Also, in a UK-based study that surveyed persons with epilepsy, a third reported difficulty accessing medical services, with $8 \%$ having had an appointment canceled. Meanwhile, medication shortages were noted by approximately $30 \%$ of neurologists in a survey of the American Epilepsy 


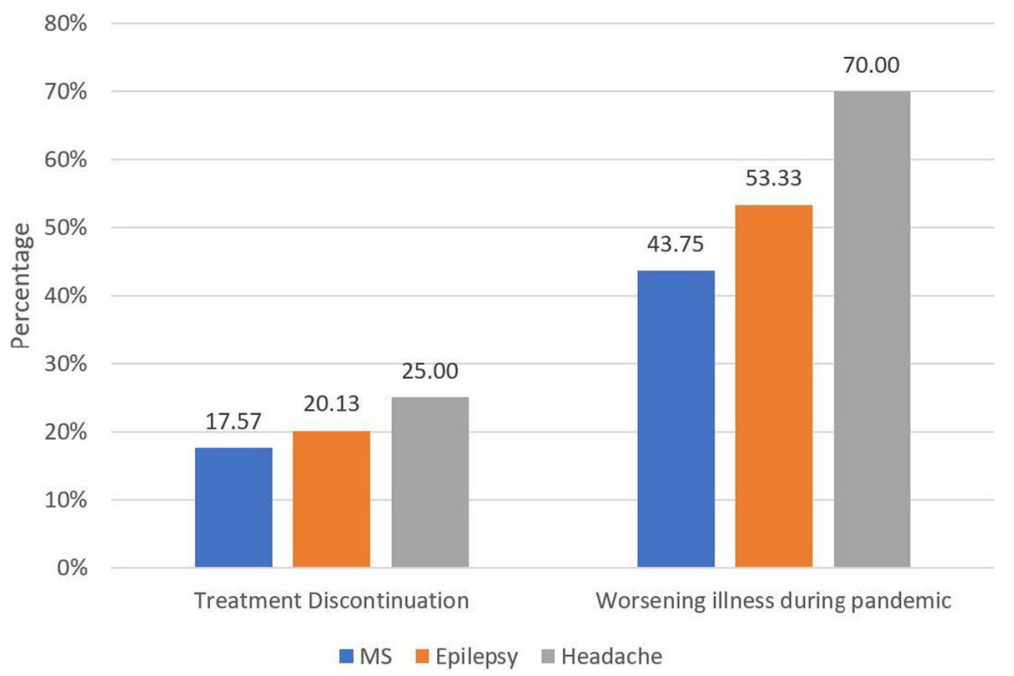

Fig. 1 Impact of the pandemic on three common neurological illnesses in Jordan. Patients with headache were most likely to report discontinuation of medication or worsening of their illness since the start of the pandemic, followed by epilepsy patients and patients with MS, respectively

Society members [19]. On the other hand, a survey of 176 MS patients from Saudi Arabia found that 15\% of the patients had a relapse but did not seek medical help because of the pandemic, while $15.9 \%$ stopped their DMTs, and 35.2\% reported missing drug infusions or refills [20]. Moreover, in a survey of 1018 persons with migraine headache from Kuwait, $59.6 \%$ of sampled patients reported an increase in migraine frequency, and $78.1 \%$ reported sleep disturbances [17].

This study is not without limitations. Although recruiting patients from outpatient clinics reduced selection bias as opposed to online surveys, it remains based on a single center and medical diagnoses were ascertained retrospectively from patient files. Additionally, the establishment of a direct causal relationship through observational surveys is difficult. Nonetheless, this study is a steppingstone for future efforts in this regard.

\section{Conclusion}

The impacts of COVID-19 pandemic on neurology patients in Jordan are diverse and evident across the spectrum of neurological illnesses. More studies are necessary to further delineate the impacts of pandemic on other aspects of health services in the country and, importantly, to draw appropriate conclusions for the future.

\section{Abbreviations}

SARS: Severe acute respiratory syndrome; COVID-19: Coronavirus disease of 2019; SARS-CoV-2: Severe acute respiratory syndrome coronavirus 2; MS: Multiple sclerosis; DMT: Disease-modifying treatment; ASM: Anti-seizure medication

\section{Acknowledgements}

Not applicable.

\section{Authors' contributions}

$M A, Q S, B A$, and WB designed the study and conducted literature review. MA and QS collected the data. All authors contributed to data interpretation and writing the manuscript. BA and YK prepared the tables and graph. All authors have read and approved the manuscript.

\section{Authors' information}

MA is Assistant Professor of Neurology at the Yarmouk University Faculty of Medicine. QS and WB are Neurologists at Princess Basma Teaching Hospital. BA is a 5th year neurology resident at the King Abdullah University Hospital of Jordan University of Science and Technology. YK is Professor at the Department of Public Health and Community Medicine of Jordan University of Science and Technology. He is the top cited scholar in Jordan, with over 110,000 scholarly citations as of February 1st, 2021.

Funding

None.

Availability of data and materials

Available from Mohammad Athamneh upon reasonable request.

\section{Declarations}

Ethics approval and consent to participate

Ethical approval for the study was granted by IRB Committee at Yarmouk University under IRB number 2020/125/78. Written consent to participate was obtained from each participant upon completion of the survey.

\section{Consent for publication}

Not applicable.

\section{Competing interests}

The authors declare that they have no competing interests.

\section{Author details}

'Department of Neuroscience, Faculty of Medicine, Yarmouk University, Irbid, Jordan. ${ }^{2}$ Department of Neurology, Princess Basma Teaching Hospital, Irbid, Jordan. ${ }^{3}$ Department of Neuroscience, Faculty of Medicine, Jordan University of Science and Technology (JUST), Irbid, Jordan. ${ }^{4}$ Department of Public Health and Community Medicine, Jordan University of Science and Technology, Irbid, Jordan. 
Received: 10 February 2021 Accepted: 13 July 2021

Published online: 29 July 2021

\section{References}

1. Parpia AS, Ndeffo-Mbah ML, Wenzel NS, Galvani AP. Effects of response to 2014-2015 Ebola outbreak on deaths from malaria, HIV/AIDS, and tuberculosis. West Afr Emerg Infect Dis. 2016;22(3):433-41. https://doi.org/ 0.3201/eid2203.150977

2. Chu D, Chen R-C, Ku C-Y, Chou P. The impact of SARS on hospital performance. BMC Health Serv Res. 2008;8(1):228. https://doi.org/10.1186/14 72-6963-8-228.

3. Al Kuwari M, Abdulmalik M, Al Abdulla S, Haj Bakri A, Gibb J, Kandy M. The COVID-19 pandemic impact on primary health care services: an experience from Qatar. 2020. https://www.medrxiv.org/content/10.1101/2020.07.22.201 60333v1. Accessed 25 Feb 2021.

4. Coma E, Mora N, Méndez L, Benítez M, Hermosilla E, Fàbregas M, et al. Primary care in the time of COVID-19: monitoring the effect of the pandemic and the lockdown measures on 34 quality of care indicators calculated for 288 primary care practices covering about 6 million people in Catalonia. BMC Fam Pract. 2020;21(1):208. https://doi.org/10.1186/s12875-02 0-01278-8

5. Santoli JM, Lindley MC, DeSilva MB, Kharbanda EO, Daley MF, Galloway L, et al. Effects of the COVID-19 pandemic on routine pediatric vaccine ordering and Administration - United States, 2020. MMWR Morb Mortal Wkly Rep. 2020;69(19):591-3. https://doi.org/10.15585/mmwr.mm6919e2.

6. Zhou Z, Kang H, Li S, Zhao X. Understanding the neurotropic characteristics of SARS-CoV-2: from neurological manifestations of COVID-19 to potential neurotropic mechanisms. J Neurol. 2020;267(8):2179-84. https://doi.org/10.1 007/s00415-020-09929-7.

7. Flores G. SARS-COV-2 (COVID-19) has neurotropic and neuroinvasive properties. Int J Clin Pract. 2021;75(2):e13708. https://doi.org/10.1111/ ijcp. 13708.

8. Jarrahi A, Ahluwalia M, Khodadadi H, da Silva Lopes Salles E, Kolhe R, Hess DC, et al. Neurological consequences of COVID-19: what have we learned and where do we go from here? J Neuroinflammation. 2020;17(1):286.

9. Favas $\Pi$, Dev P, Chaurasia RN, Chakravarty K, Mishra R, Joshi D, et al. Neurological manifestations of COVID-19: a systematic review and metaanalysis of proportions. Neurol Sci. 2020;41(12):3437-70. https://doi.org/10.1 007/s10072-020-04801-y.

10. Kovvuru S, Nalleballe K, Onteddu SR, Sharma R, Jasti M, Kapoor N, et al. Immunosuppression in chronic autoimmune neurological disorders during the COVID-19 pandemic. J Neurol Sci. 2021;420:117230. https://doi.org/10.1 016/j.jns.2020.117230.

11. Bertran Recasens B, Rubio MA. Neuromuscular Diseases Care in the Era of COVID-19. Front Neurol. 2020;11:588929. https://doi.org/10.3389/ fneur.2020.588929.

12. Alqutob R, Al Nsour M, Tarawneh MR, Ajlouni M, Khader $Y$, Aqel I, et al. COVID-19 Crisis in Jordan: Response, Scenarios, Strategies, and Recommendations. JMIR Public Health Surveill. 2020;6(3):e19332. https://doi. org/10.2196/19332.

13. Massad I, Al-Taher R, Massad F, Al-Sabbagh MQ, Haddad M, Abufaraj M. The impact of the COVID-19 pandemic on mental health: early quarantinerelated anxiety and its correlates among Jordanians. East Mediterr Health J. 2020:26(10):1165-72. https://doi.org/10.26719/emhj.20.115.

14. Sallam M, Dababseh D, Yaseen A, Al-Haidar A, Taim D, Eid H, et al. COVID-19 misinformation: Mere harmless delusions or much more? A knowledge and attitude cross-sectional study among the general public residing in Jordan. PLoS One. 2020;15(12):e0243264. https://doi.org/10.13 71/journal.pone.0243264.

15. Cinelli M, Quattrociocchi W, Galeazzi A, Valensise CM, Brugnoli E, Schmidt AL, et al. The COVID-19 social media infodemic. Sci Rep. 2020;10(1):16598. https://doi.org/10.1038/s41598-020-73510-5.

16. Mostacci B, Licchetta L, Cacciavillani C, Di Vito L, Ferri L, Menghi V, et al. The impact of the COVID-19 pandemic on people with epilepsy. An Italian Survey and a Global Perspective. Front Neurol. 2020;11:613719.

17. Al-Hashel JY, Ismail II. Impact of coronavirus disease 2019 (COVID-19) pandemic on patients with migraine: a web-based survey study. Headache Pain. 2020;21(1):115. https://doi.org/10.1186/s10194-020-01183-6.

18. Thorpe J, Ashby S, Hallab A, Ding D, Andraus M, Dugan P, et al. Evaluating risk to people with epilepsy during the COVID-19 pandemic: Preliminary findings from the COV-E study. Epilepsy Behav. 2021;115:107658. https://doi. org/10.1016/j.yebeh.2020.107658.

19. Albert DVF, Das RR, Acharya JN, Lee JW, Pollard JR, Punia V, et al. The Impact of COVID-19 on Epilepsy Care: A Survey of the American Epilepsy Society Membership. Epilepsy Curr. 2020;20(5):316-24. https://doi.org/10.11 77/1535759720956994.

20. Alnajashi $H$, Jabbad R. Behavioral practices of patients with multiple sclerosis during Covid-19 pandemic. PLoS One. 2020;15(10):e0241103. https://doi. org/10.1371/journal.pone.0241103.

\section{Publisher's Note}

Springer Nature remains neutral with regard to jurisdictional claims in published maps and institutional affiliations.

\section{Submit your manuscript to a SpringerOpen ${ }^{\circ}$ journal and benefit from:}

- Convenient online submission

- Rigorous peer review

- Open access: articles freely available online

High visibility within the field

- Retaining the copyright to your article

Submit your next manuscript at $\boldsymbol{\nabla}$ springeropen.com 